\title{
Temperature based phenology model for predicting establishment and survival of Spodoptera litura (Fab.) on groundnut during climate change scenario in India
}

\author{
M.SRINIVASA RAO* and T.V.PRASAD \\ ICAR-Central Research Institute for Dryland Agriculture, Hyderabad, 500059 Telangana \\ *Corresponding author's e-mail: msrao909@gmail.com
}

\begin{abstract}
Studies were conducted to develop temperature-based phenology model for Spodoptera litura on groundnut, at both constant and fluctuating temperatures and to predict the possibility of pest risk in future climate change scenarios of India using 'stochastic simulation tool' in Insect Life Cycle Modelling (ILCYM) software ,which is based on rate summation and cohort up-dating approach. Phenology model predicted temperatures between $25^{\circ} \mathrm{C}$ and $30^{\circ} \mathrm{C}$ as the favourable range for $\mathrm{S}$. litura development, survival and reproduction. The intrinsic rate of increase $(\mathrm{rm})$, and finite rate of increase (») increased with increase in temperature from $15^{\circ} \mathrm{C}$ to $30^{\circ} \mathrm{C}$ and decreased with increase in temperature. Intrinsic rate of increase $(\mathrm{rm})$, varied from 0.05 females/female/day at $15^{\circ} \mathrm{C}$ to 0.17 females/female/day at $30^{\circ} \mathrm{C}$. S. litura population attained a maximum net reproductive rate ' $R_{0}$ ' (334.09 females/female/generation) and total fecundity (1041.88 individuals/ female/generation) at $27^{\circ} \mathrm{C}$ temperature. Simulated life table parameters were used to determine indices such as the establishment risk index (ERI), the generation index $(\mathrm{GI})$, and activity index (Al) by using the 'Population distribution and risk mapping' module of software during present and future climatic scenarios and significant increase in AI and ERI with higher GI at future (2050) climatic conditions compared to current (2000) climatic conditions indicating the strong suitability for establishment and survival of S.litura in India.
\end{abstract}

Keywords: Life table, S.litura, phenology model, temperature, establishment risk index

Spodoptera litura (Fabricius), tobacco caterpillaris a serious and devastating polyphagous insect pest causing considerable losses to many economically important cultivated crops including groundnut (Qin et al., 2004) and loss of major crops due to insect pest varies between 10 and $30 \%$.To develop any pest management programme for a specific agro-ecosystem, information on abundance and distribution of pest in relation to weather parameters is a basic requirement (Patel and Shekh, 2006). Activity of S.litura in relation to weather factors have been investigated by many workers (Nandagopal et al., 2006; Prasad et al., 2013; Ramesh Babu et al., 2015). Incidence of insect pests is driven by various environmental factors and temperature is one of the most important factors that influences significantly. Temperature is a key abiotic factor influencing survival and reproduction rates in insects and hence strongly determines the pest's demographic parameters, which are essential for interpreting population dynamics, developmental rates and seasonal occurrence. Detailed knowledge on temperature effects on herbivore insect pests can be used to determine the range where the pest might develop (establish) and to predict the population's growth potential (i.e. intrinsic rate of increase) and dynamics. In fact, each pest management programme requires authentic determination of the pest's population parameters (Zamani et al., 2006). The ability of an insect to develop at different temperatures is an important adaptation to survive in various climatic conditions, and its understanding is important for predicting pest outbreaks (Gilbert and Raworth, 1996). The temperature response phenology models simulate the variability in insect development times within a population based on the detailed laboratory assessments of the insect's life history and thus, can provide better results on future pest activity (Wagner $e t$ al., 1984). Phenology models that use non-linear functions of higher biological significance and include stochastic functions for simulating variability in development times within a population can provide better results than linear models (Sporleder et al., 2004). The pest forecasting models facilitate better preparedness to combat outbreaks of serious insect pests by developing effective pest management strategies well in advance.

The objective of present study was to develop an inclusive temperature-dependent population growth model for S. litura, which permits prediction of its population growth potential and will also help in future population growth potential under probable climate change. 


\section{MATERIALS AND METHODS}

\section{Insect cultures}

During the rainy seasons of 2016 and 2017, egg masses and larval population of S. litura were collected from the groundnut fields of Hayathnagar Research Farm of ICAR-Central Research Institute for Dryland Agriculture (CRIDA), Hyderabad, Telangana in India (Location: $17.32^{\circ}$ $\mathrm{N}, 78.59^{\circ} \mathrm{E}$, Alt. $\left.566 \mathrm{~m}\right)$. For mass multiplication of $S$. litura the insect culture was maintained in glass jars $(15 \mathrm{~cm} \times 10 \mathrm{~cm})$ at controlled temperature and humidity conditions of $27 \pm$ $2{ }^{\circ} \mathrm{C}$ and $65 \pm 5 \% \mathrm{RH}$ and natural photoperiod in the insectary of Entomology laboratory, ICAR-CRIDA, Hyderabad. The larvae were reared on groundnut leaves for one generation (from egg to egg) to obtain bulk population for further experimentation. The pupae were transferred to pupation jars containing a 2-3 cm layer of moist sterilized sand covered with filter paper. Just after emergence, the adults were shifted to oviposition jars similar to pupation jars but lined with filter paper on the inner side to facilitate egg laying. The adults were fed on water and honey solution $(4: 1 \mathrm{v} / \mathrm{v})$ soaked on a cotton swab.

Experiments on life tables were conducted at temperatures of $15,20,25,27,30,33$ and $35^{\circ} \mathrm{C}$. In order to construct life tables, a group of newly laid eggs of $S$. litura were placed on a piece of wet filter paper in Petri dish $(75 \mathrm{x}$ $10 \mathrm{~mm}$ ). These Petri dishes were maintained at seven different temperatures $\left(15,20,25,27,30,33\right.$ and $\left.35^{\circ} \mathrm{C}\right)$ in growth chambers (I 36LL; Percival Scientific, Inc. Perry, USA) at 75 $\pm 5 \%$ relative humidity with a photoperiod ratio of $14: 10$ (14 hours of light: 10 hours of dark). After egg hatching, the egg period was recorded at different temperatures. Freshly hatched neonates (thirty) were collected and experimental trials were initiated. Freshly hatched thirty neonates were reared individually in Petridishes $(75 \times 10 \mathrm{~mm})$ till the adult stage. Larvae were fed with fresh groundnut leaves collected from fields. The data on durations of egg, larval, pupal and adult and total development periods at each temperature were recorded.

\section{Modelling and simulation tools}

The Insect Life Cycle Modelling (ILCYM) software version 3.0, developed by the International Potato Centre,Lima, Peru(https://research.cip.cgiar.org/ confluence/displayilcym/Downloads (Tonnang et al., 2013) was used for the development of process-based temperaturedriven and age-stage structured $S$. litura phenology model.

\section{Development time and its distribution}

The cumulative frequencies of development times of each life stage and temperatures were plotted against normalized developmental times by fitting a complementary log-log (CLL) distribution curve for all stages. The mathematical expressions of distribution function (Tonnang et al., 2013)is given as: CLL distribution: $\mathrm{F}(\mathrm{x})=1-\exp (-\exp$ $\left.\left(\mathrm{a}_{\mathrm{i}}+b \ln \mathrm{x}\right)\right)$, where, $\mathrm{F}(\mathrm{x})$ is the probability to complete development at time $\mathrm{x}, \ln \mathrm{x}$ is the natural logarithm of the days observed, a is the intercept corresponding to temperature $\mathrm{i}$, and $\mathrm{b}$ is the common slope of the regression model. The best fit model was selected based on Akaike's Information Criterion (AIC), a well-known goodness of fit indicator (Akaike, 1973).

\section{Development rate}

Inverse of durations of immature development and adult survival (1/days) were taken as rates of development and survival, respectively. The non-linear regression model was fitted to establish the relationship between development rate and temperature (Zajac et al., 1989). The modified fourteen parameter version of Sharpe and DeMichele model was used for estimating rates of egg development(Sharpe and DeMichele, 1977) and Janish 2, function was fitted to larvae and pupa of S.litura at various constant temperatures.

\section{Immature stages mortality and adult senescence}

Mortality was calculated from the frequency of cohort mortality. The mortality in immature stages of $S$. litura at various constant temperatures was estimated by applying modified version of the Wang model (Wang et al., 1982). The relationship between senescence of adults of $S$. litura at various constant temperatures was determined by fitting a modified fourteen parameter version of Sharpe and DeMichele model (Stinner et al., 1974).

\section{Temperature dependent reproduction}

The oviposition was modelled considering the three temperature dependent functions: temperature dependent total fecundity, age-related oviposition frequency and agespecific adult survival. Anon-linear regression model, Taylor 2 was fitted to find out the effects of various constant temperatures on total number of eggs produced by a female adult during her whole life span (Kim and Lee, 2003).The relationship between cumulative oviposition rate and female age was well described by the Gamma function.

Estimationof life table parameters at constant temperatures Using 'stochastic simulation tool' in ILCYMwhich is 
based on rate summation and cohort up-dating approach (Curry et al., 1978), the life table parameters viz., gross reproductive rate (GRR), net reproductive rate (Ro), intrinsic rate of natural increase ( $\mathrm{rm})$, finite rate of increase ( $)$, mean generation time $(\mathrm{T})$ and doubling time $(\mathrm{Dt})$ were estimated. The estimates were based on the developed phenology model at seven constant temperatures ranging $15-35^{\circ} \mathrm{C}$ with five repetitions each.

\section{Comparison of life tables at constant and fluctuating temperatures}

The life table data on S. litura obtained from fluctuating temperature experiment were compared with model outputs produced using constant temperature experiments. The stochastic simulation based on rate summation and cohort updating approach (Curry et al., 1978) was used in estimating life history parameters.

\section{Estimation of pest risk indices}

Using values of the life table parameters, we calculated Establishment risk index (ERI), Generation index (GI) and Activity index (AI) for possible pest risk at each data point (Tonnang et al., 2013):

\section{Spatial mapping of risk indices}

The risk indices thus estimated were employed in the "potential population analysis and mapping" module of ILCYM for visualizing the risk maps. The module facilitated spatial simulations of pest populations through grid-based within a deûned area according to grid-speciûc monthly temperatures interpolated from available databases (worldclim in this case) (Tonnang et al., 2013). The process generated ASCII ûles (.asc) which were converted to grid format (.grd) for visualizing the risk maps by importing in DIVA-GIS (an open source geographic information system, downloadable at http://www.diva-gis.org).

\section{RESULTS AND DISCUSSION}

\section{Effects of temperature on development time and survivorship}

At different temperatures, the data on development duration for immature and adult stages of $S$. litura are presented in Table 1. The temperatures within the evaluation range have a greater influence on the development of the immature life stages of S. litura. Results indicated that, the duration of the immature stages and the time required completing the cycle from egg to adult decreased significantly with increasing temperatures within the temperature range of $15-33^{\circ} \mathrm{C}$ (Table 1) and became non- 
Table 2: Estimated life table parameters of S. litura at different constant temperatures

\begin{tabular}{lrrrrrr}
\hline $\begin{array}{l}\text { Temperature } \\
\left({ }^{\circ} \mathrm{C}\right)+0.5\end{array}$ & $\begin{array}{r}\text { Intrinsic } \\
\text { rate of } \\
\text { increase }(\mathrm{rm})\end{array}$ & $\begin{array}{r}\text { Net } \\
\text { reproductive } \\
\text { rate (R0) }\end{array}$ & $\begin{array}{r}\text { Gross } \\
\text { reproductive } \\
\text { rate (GRR) }\end{array}$ & $\begin{array}{r}\text { Mean } \\
\text { generation } \\
\text { time }(\mathrm{T})\end{array}$ & $\begin{array}{r}\text { Finite } \\
\text { rate of } \\
\text { increase (?) }\end{array}$ & $\begin{array}{r}\text { Doubling } \\
\text { time } \\
(\text { days })\end{array}$ \\
\hline 15 & 0.05 & 0.01 & 1.70 & 73.23 & 0.94 & 12.79 \\
20 & 0.05 & 30.83 & 445.00 & 61.98 & 1.05 & 12.53 \\
25 & 0.13 & 291.82 & 991.57 & 42.75 & 1.14 & 5.22 \\
27 & 0.15 & 334.09 & 1041.88 & 37.09 & 1.16 & 4.42 \\
30 & 0.17 & 185.33 & 825.46 & 30.55 & 1.18 & 4.05 \\
33 & 0.13 & 40.55 & 552.36 & 27.74 & 1.14 & 5.19 \\
35 & 0.06 & 8.07 & 323.99 & 32.02 & 1.06 & 6.63 \\
\hline
\end{tabular}
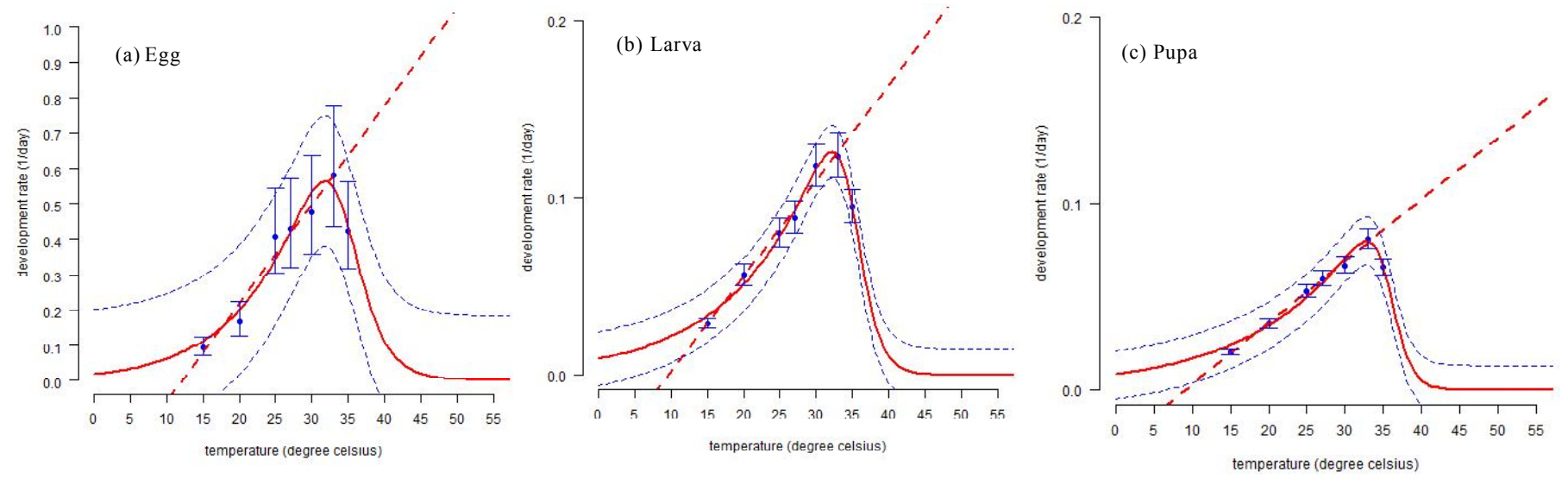

Fig.1: Temperature-dependent developmental rates (1/ day) for immature stages of S. litura. (a)Egg; Sharpe \& DeMichele 14. (b) Larva and (c) Pupa; Janish 2. The bold solid line is the selected model output and dashed lines above and below represents the upper and lower $95 \%$ confidence bands. Bars represent standard deviation of the mean.
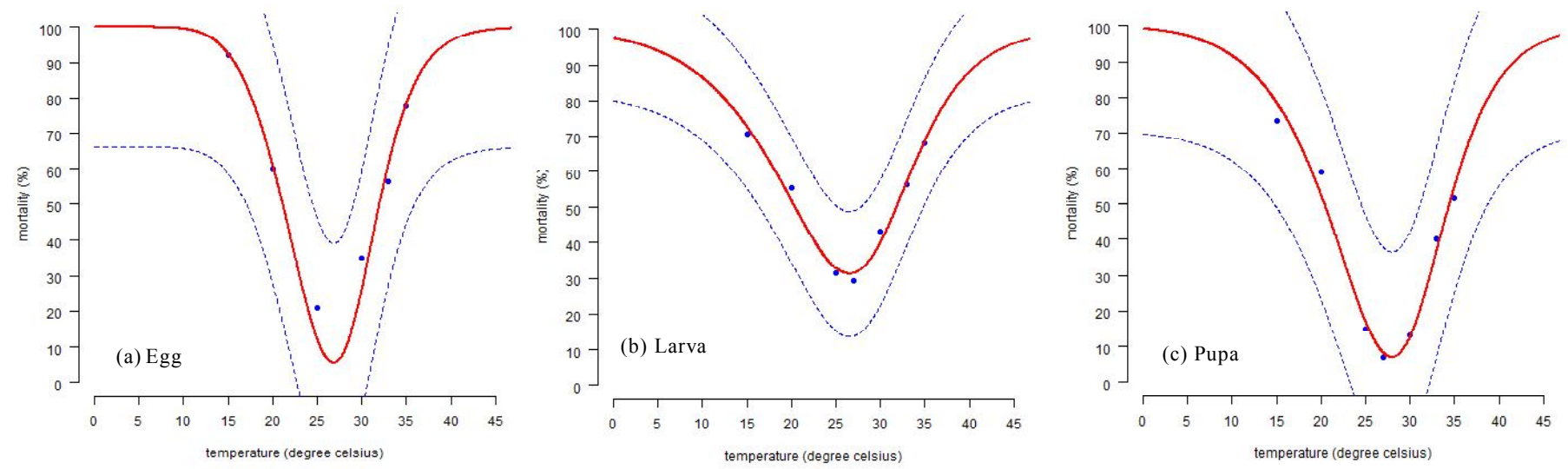

Fig.2: Temperature dependent mortality rate of immature life stages of S. litura. (a) Egg(b) Larva; Wang 8 and (c)Pupa; Wang 7. Fitted curves: Non-linear model for all immature stages. The upper and lower $95 \%$ confidence intervals of the model are indicated.

linear at $35^{\circ} \mathrm{C}$ temperature. The cumulative frequencies of development times of each life stage and temperatures were plotted against normalized development times by fitting a linear binomial distribution curve for immature stages and adult stages of $S$. litura. Decrease in immature development time from low to high temperatures till $33^{\circ} \mathrm{C}$ was noted. The observed mean development times for all the immature life stages were fastest at $33^{\circ} \mathrm{C}$ (Egg: $2 \pm 0.13$; Larva: $13 \pm 0.24$; Pupa: $8 \pm 0.26$ ), and lowest at $15^{\circ} \mathrm{C}$ (Egg: $12.0 \pm 0.51$; Larva: $51.0 \pm 0.65$; Pupa: $36.0 \pm 1.19$ ). 
AI 2000

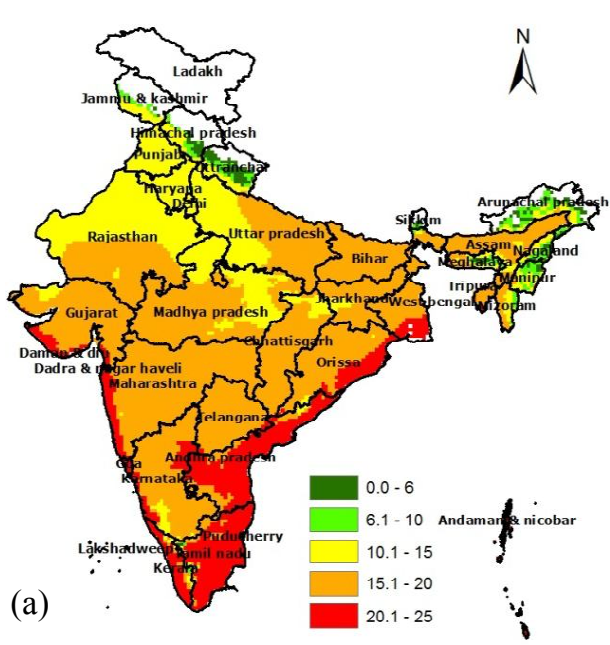

Predicted AI 2050

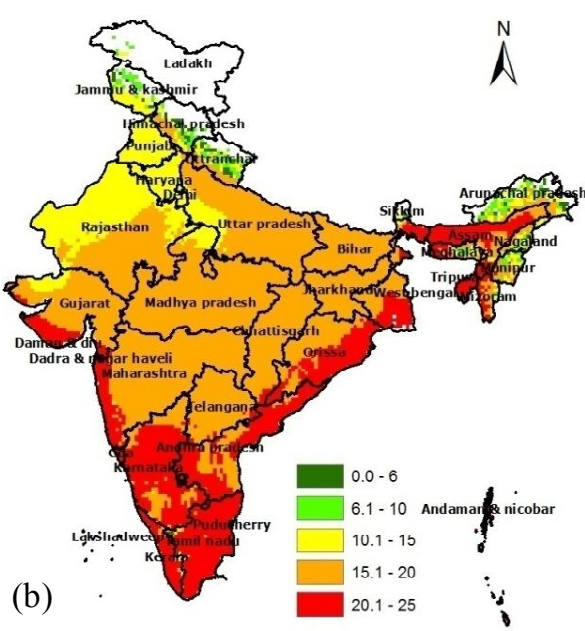

Difference between 2050 and 2000 - AI

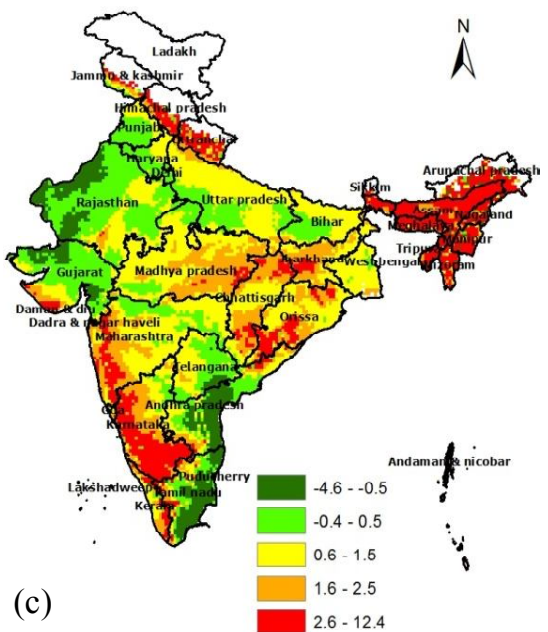

Fig.3: Change in abundance and damage potential of S. litura in groundnut production areas of India based on activity index (AI) for (a) current (b) future climatic conditions and(c) difference between the current and future climatic conditions.

Among various abitoic factors that influence insect pests, temperature plays a vital role on different life history traits; including development time, longevity and fecundity. Thus, reduction of longevity or duration of an insect with increase in temperature occurs due to the accelerated use of energy (Tommaso et al.,2007) and similar trend of reduction of duration was observed in our study.The developmental durations of S. litura immature stages observed at different constant temperatures were in conformity with earlier reports of Fand et al.(2014) and Srinivasa Rao et al.(2014). The mean development time (days) of each stage and total life span decreased from $15^{\circ} \mathrm{C}$ to $33^{\circ} \mathrm{C}$ temperature. A similar decrease in development period with an increase in constant temperatures was reported in case of other lepidopteran insect pests such as Elasmopalpus lignosellus (Hardev et al., 2013) and S. litura (Srinivasa Rao et al., 2014). The life table parameters of lepidopteran insect pests are influenced by kind of host plant (Yasar and Güngör, 2005; Kumar et al., 2009) and quality of the diet (Jallow and Matsumara, 2001). The availability of quality host plant will play significant role in insect pest population dynamics by influencing the different life stages (Yasar and Gungor, 2005).

\section{Effects of temperature on development rate}

Inverse of durations of immature development and adult survival (1/days) were taken as rates of development and survival, respectively. Development rate as a function of temperature, increased monotonically for all the immature stages (egg, larva and pupa) until $33^{\circ} \mathrm{C}$. For describing the temperature dependence of development rate of egg stage fourteen parameters version of the Sharpe and DeMichele was used (Sharpe and DeMichele, 1977) and Janish 2, function was fitted to larvae and pupa of S.litura at various constant temperatures. The thermal reaction norms were well fitted by the modified fourteen parameter version of Sharpe and DeMichele model as indicated by the smallest value of AIC (-16.0) and highest value of coefficient of determination $(>0.92)$ for egg stage, Janish 2 were well fitted for larvae and pupa with smallest value of AIC (Larva: AIC of -53.28; Pupa:AIC of -51.04)and highest valueof coefficient of determination(Larva: $\mathrm{R}^{2}>0.91$; Pupa: $\mathrm{R}^{2}>0.92$ ), respectively (Fig 1). The senescence rate for both the female and the male adults increased linearly from low to high temperatures. The modified fourteen parameter version of Sharpe and DeMichele model for male and female provided a good fit to the observed mean senescence rates for both the adult sexes.

\section{Immature survival at constant temperatures}

The temperature dependent mortality rates for egg and larva of $S$. litura were well fitted by the Wang 8 model as indicated by the smallest value of AIC (Egg: <-14.3; Larva: < -21.6) and highest value of coefficient of determination (Egg: $>0.97$; Larva: $>0.96$ ) respectively and for pupal stage of S. litura, Wang 7 model were well fitted as indicated by the smallest value of AIC (Egg: < -7.4) and highest value of coefficient of determination(Egg :> 0.95). The optimum temperature for survival of immature life stages of $S$. lituraare within the range of 25 to $33{ }^{\circ} \mathrm{C}(>70 \%$ survival of all the immature stages). Temperature significantly influenced immature survival in S. litura. At constant temperature of $15^{\circ} \mathrm{C}$, the egg and larval survival ranged between $18-23 \%$, whereas only $5.0 \%$ of the pupae could survive to become adults at this low temperature. The 
survival rates of S. litura immature stages varied significantly at various constant temperatures. The constant temperatures below $20^{\circ} \mathrm{C}$ and above $33^{\circ} \mathrm{C}$ were highly unfavourable for survival of all the immature life stages, where increased mortality rates were observed. In the present study, we could obtain highest percentage of survival (65.0\%) in S. litura larva when reared at constant temperature of $30^{\circ} \mathrm{C}$ in laboratory. Manimanjari et al. (2014) reported the similar trend in survivorship of S. litura wherein they found lowest and highest survival at $20^{\circ} \mathrm{C}$ and $30^{\circ} \mathrm{C}$ temperatures, respectively when reared on sunflower. Further, the survival rates of immature stages of $S$. litura are highly dependent on host plants used for larval feeding (Xue et al., 2010).

\section{Temperature dependent reproduction}

The temperature influenced significantly the reproductive traits in S. litura. Eggs were produced by females from temperature regimes between $15-35^{\circ} \mathrm{C}$, with the minimum number of total eggs per female at $15^{\circ} \mathrm{C}(116.3)$ and peak egg laying at $27^{\circ} \mathrm{C}(1701.1)$ in their gonotrophic cycle. Egg laying was lowest at $15^{\circ} \mathrm{C}$ decreased with increase in temperature after $30^{\circ} \mathrm{C}$, indicating the unsuitability of temperatures below and above this range for its oviposition.

A linear response was observed for fecundity with a maximum at $27^{\circ} \mathrm{C}$ and decreasing at lower temperatures. This demonstrates that prevalence of optimum temperature can play a bigger role in determining the suitability of climate for the mating and oviposition of S. litura adults. Fairly similar trend in temperature dependent fecundity of S. litura was reported by earlier workers, who found temperatures between $25-30^{\circ} \mathrm{C}$ as suitable range for $S$. litura reproduction, and temperatures $>33^{\circ} \mathrm{C}$ were highly detrimental (Manimanjari et al., 2014). Accordingly, a significant effect of temperature on mean total fecundity was identified by fitting Taylor 2 model.

The relationship between cumulative oviposition rate and female age was well described by the Gamma function. This study presents only the effect of temperature on S. litura fecundity on groundnut. However, fecundity is also influenced by several other factors such as host nutritional quality, food availability, nutrition of immature stages, and abiotic factors like light intensity, relative humidity, etc. (Garad et al., 1984; Shahout et al., 2011; Patil et al., 2014).

\section{Life table parameters at constant temperature}

Finite (») and intrinsic rates of increase $\left(\mathrm{r}_{\mathrm{m}}\right)$, net reproductive rate $\left(\mathrm{R}_{\mathrm{o}}\right)$, mean generation time $(\mathrm{T})$ and doubling time (DT) of S. litura varied significantly with temperature and were found to have quadratic relationship with temperature (Table 2). Finite rate of increase (») which is the indicator of reproductive value of new egg was highest at $30^{\circ} \mathrm{C}$ and thereafter showed a negative relationship with temperature. The intrinsic rate of increase $(\mathrm{rm})$, and finite rate of increase (») increased with increase in temperature from $15^{\circ} \mathrm{C}$ to $30^{\circ} \mathrm{C}$ and decreased with increase in temperature. Intrinsic rate of increase $(\mathrm{rm})$, varied from 0.05 females/female/day at $15^{\circ} \mathrm{C}$ to 0.17 females/female/day at $30^{\circ} \mathrm{C}$. The findings of study are in agreement with Tuan et al., (2013) who reported ' $r_{\mathrm{m}}$ ' values of $S$. litura in the range of 0.13-0.18 on groundnut. An increase in mortality with decrease or increase in temperature indicates the non-linear relationship. The suitable range for $S$. litura reproduction was observed between $25-30^{\circ}$ C.S. litura population attained a maximum net reproductive rate ' $\mathrm{R}_{0}$ ' (334.09 females/female/generation) and total fecundity (1041.88 individuals/ female/generation) at $27^{\circ} \mathrm{C}$ temperature. After that the net reproductive rate and gross reproductive ratedecreased with increase in temperature; at higher temperatures less fecundity was recorded. Similar finding were also reported by Guang et al.,(2000).

Intrinsic rate of increase $\left(\mathrm{r}_{\mathrm{m}}\right)$ and finite rate of increase (») were maximum at $30^{\circ} \mathrm{C}$ with values of $0.17 \pm 0.002$ and $1.18 \pm 0.003$, respectively. Discrepancies occurred between $\mathrm{r}_{\mathrm{m}}$ and $\mathrm{Ro}\left(\mathrm{r}_{\mathrm{m}}\right.$ is a function of Ro) predicted from this study and those reported in literature. It seems that these discrepancies are largely due to the deviations from the selected sub-model for development and mortality of immature stages and total fecundity per female, which are considered to be the most variable factors (Sporleder et al., 2004). Besides, host material i.e. groundnut leaves used in rearing $S$. litura adds further to the variability in life cycle (Xue et al., 2010; Fand et al., 2014). Values estimated for ' $\mathrm{T}$ ' indicate that the mean length of generations decreased from 73.23 days at $15^{\circ} \mathrm{C}$ temperature to minimum of 27.74 days at $33^{\circ} \mathrm{Cand}$ shortest doubling time was observed at $33^{\circ} \mathrm{C}(5.19 \pm 0.05$ days). Fitting of a polynomial model to the estimated life table parameters predicted temperatures between $27-33^{\circ} \mathrm{C}$ as a favourable range for $S$. litura development, survival and reproduction, where high reproductive potential and shorter generation length were observed. From our findings it is understood that the ' $r_{m}$ ' and '»' increased with increase in temperature from $15^{\circ} \mathrm{C}$ and later started declining from $33^{\circ} \mathrm{C}$ with increase in temperature. The ' $r_{m}$ ' gradually increases with temperature until some threshold, after which it decreases abruptly.Decrease of 
development time with increase in temperature causes increase in ' $\mathrm{r}$ ' ' with temperature as reported by Iranipour (2010) and sugar cane pest Elasmopalpus linosellus(Hardev et al., 2013).

The present results revealed that the association between temperature and life table parameters was nonlinear relation. Many empirical models by incorporating ' $r_{\mathrm{m}}$ ' as a key parameter were used for prediction of population dynamics of insect pests. Similar approach of using laboratory measurements of temperature was adopted by Tshiala et al. (2012) to model the empirical relationship between life table parameters and temperature and assessed the impact of climate change on leaf miner. Temperature driven phenology models developed using laboratory information can be used for projection of status of future insect population (Vincent et al., 1997). The present study aimed to quantify the relationship between life table parameters and temperature and further used for predicting the pest population under present and future climate change scenarios.

Validation of phenology model at fluctuating temperatures

The range of diurnal temperature fluctuations used in generating life table data for S. litura extended between 21.7-30.2 ${ }^{\circ} \mathrm{C}$ with a mean temperature of $25.5 \pm 0.4^{\circ} \mathrm{C}$. Validation of the phenology model was conducted by comparing modeling results with experimental one-cycle life-table data obtained from fluctuating temperature studies.

\section{Estimation of pest risk indices}

Simulated life table parameters were used to determine indices such as the establishment risk index (ERI), the generation index (GI), and activity index (AI) by using the 'Population distribution and risk mapping' module of ILCYM software. The ERI index characterizes geographical areas by their capacity to assure $S$. litura survival. The maximum value of ERI is 1, means that all the immature stages are able to survive throughout the year at varied proportions. The likelihood of survival and establishment reduces considerably for the areas deviating from this ERI maximum. Similarly, GI is an estimate of the mean number of generations that a given insect pest can produce within a year. At high temperatures, the generation duration decreases meaning more generations per year and an increment of population gross number (Tonnang et al., 2013; Fand et al., 2015). The average number of generations that $S$. litura population can complete in a year under the current (2000) and the future (2050) climatic conditions are determined using the third module of
ILCYM. The results indicated significant increase in activity index and establishment risk index at future (2050) climatic conditions compared to current climatic conditions (Fig 3). There is increase in the average number of generations of $S$. litura population under future (2050) climatic conditions compared to the current (2000) climatic conditions.

According to the model predictions, under the current climate conditions $S$. litura can produce maximum of 10-12 generations peryear in India. An additional two mean number of generations produced per year by S. litura under the future climatic conditions ( 2050 scenario) in India. These findings greatly support our predictions on $S$. litura number of generations per year under both current and future climatic scenarios. Every increase in GI by a value of 1.0 indicates completion of an additional generation per year and thus increases in the abundance and the damage potential of S. litura. The relationship between aspects of an insect life-history (development, survival, reproduction, etc.) and environmental variables (temperature) can be well described by process-based phenology models. These models can be used to identify environments where insects might persist and are realistic and preferable tools to predict the risks of establishment and population growth potential of insects' species. These index values will act as potential indicators to understand the distribution and abundance of insect pest. The present results indicate that temperature is vital in influencing the growth and life table parameters of S. litura and that pest incidence is likely to be higher in the future.

\section{CONCLUSION}

This study indicated that the growth and development of $S$. litura are significantly influenced by temperature. Both lower and higher temperatures limited the survival and development of insect pest and the ideal condition for the growth of the pest is at $27^{\circ} \mathrm{C}$ temperature, while the development rate increases with temperature upto $33^{\circ} \mathrm{C}$. However the life table parameters are sensitive to temperature which is major factor of climate change. In the present study pest risk indices are simulated using the pests' process-based phenology model that describes the basic physiological principals of insect species' growth, i.e. its development, survival and reproduction. The model discussed here might be used as a tool for specific pest risk assessments and for improving pest management strategies for $S$. litura. Furthermore, all other possible sources of uncertainty (e.g. predictions of climate change, future host plant distribution, 
etc.) in making the predictions on S. litura distribution, abundance and its response to future climatic changes warrant more detailed insights into the abiotic and biotic factors that impact the species population growth and spatiotemporal abundance.

\section{ACKNOWLEDGEMENTS}

This work was financially supported by grants from the Indian Council of Agricultural Research (ICAR), New Delhi in the form of National Initiative on Climate Resilient Agriculture (NICRA) Project. The authors are thankful to the Director, ICAR-CRIDA and Head, Division of Crop Sciences, ICAR-CRIDA, Hyderabad for providing necessary facilities in carrying out the research. The authors are also thankful to Dr. Jaipal Singh Choudhary, Scientist (Entomology) ICARResearch Complex for Eastern Region (ICAR-RCER), Patna for critical inputs and improving the quality of the manuscript.

\section{REFERENCES}

Akaike, H. (1973). Information theory as an extension of the maximum likelihood principle., pp. 267-281. In: B.N. Petrov and F. Csaki [Eds.], Second International Symposium on Information Theory, Akademiai Kiado, Budapest.

Curry, G.L., Fieldman, R.M. and Smith, K.C. (1978). Astochastic model for a temperature-dependent population. Theor. Popul. Biol., 13: 197-213.

Fand, B.B., Sul, N.T., Bal, S.K. and Minhas, P.S. (2015). Temperature impacts the development and survival of common cutworm (Spodoptera litura): Simulation and visualization of potential population growth in India under warmer temperatures through life cycle modelling and spatial mapping. PLoSOne. 10(4): e0124682.

Fand, B.B., Tonnang, H.E.Z., Kumar, M., Kamble, A.L. and Bal, S.K. (2014) A temperature-based phenology model for predicting development, survival and population growth potential of mealybug, Phenacoccus solenopsis Tinsley (Hemiptera: Pseudococcidae). Crop Prot., 55: 98-108.

Garad, G.P., Shivapuje, P.R. and Bilapate, G.G. (1984). Life fecundity tables of Spodopter alitura (F.) on different hosts. Proc. Indian. Acad. Sci., 93: 29-33.

Gilbert, N. and Raworth, D. (1996). Insects and temperature: A general theory. Can. Entomol., 128: 1-14.

Guang, H.S., Cheng, X.N. and Zhang, X.X. (2000). Simulation on developmental and survival rate of brown plant hopper nymphs. Chin. J. Rice Sci., 14 (3): 157-160.

Hardev, S.S., Garegg, S.N., Susan, E.W., Ronald, H.C. and Robert, A.G. (2013). Temperature- dependent reproductive and life table parameters of Elasmopalpus lignosellus (Lepidoptera:Pyralidae) on sugarcane. Fla. Entomol., 96 (2): 380-390.

Iranipour, S., Pakdel, A.K. and Radjabi, G. (2010). Life history parameters of the Sunn pest, Eurygaster integriceps, held at four constant temperatures. J. Insect. Sci., 10: 106.

Jallow, M.F.A. and Matsumura, M., (2001). Influence of temperature on the rate of development of Helicoverpa armigera (Hübner) (Lepidoptera: Noctuidae). Appl. Entomol. Zool., 36 (4): 427-430.

Kim, D.S. and Lee, J.H. (2003). Oviposition model of Carposina sasakii (Lepidoptera: Carposinidae). Ecol. Model., 162: 145-153.

Kumar, S., Saini, R.K. and Ram, P. (2009). Natural mortality of Helicoverpa armigera (Hübner) eggs in the cotton ecosystem. J. Agric. Sci. Technol., 11: 17-25.

Manimanjari, D., Srinivasa Rao, M., Swathi, P., Rama Rao, C.A., Vanaja, M. and Maheswari, M. (2014). Temperature and $\mathrm{CO}_{2}$-dependent life table parameters of Spodoptera litura (Noctuidae: Lepidoptera) on sun-flower and prediction of pest scenarios. J. Insect Sci., 14(297): DOI: $10.1093 /$ jisesa/ieu159

Nandagopal, V.,Prasad,T.V. and Gedia, M.V.(2006). Population dynamics of leaf eating caterpillar Spodoptera litura (Fab.) in relation to weather parameters in groundnut in Saurashtra Region. J. Agrometeorol., 8(1): 60-64.

Patel, H.R. and Shekh,A.M. (2006). Pest epidemics and role of meteorological services: An Overview. J. Agrometeorol., 8(1):104-113.

Patil, R.A., Mehta, D.M. and Jat, B.L. (2014). Studies on life fecundity tables of Spodoptera litura Fabricius on tobacco Nicotiana tabacum Linnaeus. Entomol. Ornithol. Herpetol., 3: 1-5.

Prasad,Y.G., Gayathri, M., Prabhakar, M., Jeyakumar,P., Vennila, S., Subba Rao., A.V.M., Bhaskara Rao, I., Rao, K.V. and Rao, V.U.M. (2013). Population dynamics of Spodoptera litura outbreak on soybean vis-à-vis rainfall events. $J$. Agrometeorol., 15 (Special Issue I): 37-40.

Qin, H., Qin, Z. Ye, S. Huang, J. andDing, R. Luo.(2004). The correlations of the different host plants with preference 
level, life duration and survival rate of Spodoptera litura Fabricius. Chin. J. Eco-Agric., 12: 40-42.

Ramesh Babu, S., Kalyan, R.K., Ameta, G.S. and Meghwal,M.L.(2015). Analysis of outbreak of tobacco caterpillar, Spodoptera litura (Fabricius) on soybean. $J$. Agrometeorol., 17(1): 61-66.

Shahout, H.A., Xu, J.X., Yao, X.M. and Jia, Q.D. (2011). Influence and mechanism of different host plants on the growth, development and, fecundity of reproductive system of common cutworm, Spodoptera litura (Fabricius) (Lepidoptera: Noctuidae). Asian J. Agric. Sci., 3: 291-300.

Sharpe, P.J.H., Curry, G.L. and DeMichele, D.W. (1977). Distribution models of organism development times. $J$. Theor. Biol., 66: 21-38.

Sporleder, M., Kroschel, J., Gutierrez, Q.M.R. and Lagnaoui, A. (2004). A Temperature-based simulation model for the potato tuberworm, Phthorimaeaoperculella Zeller (Lepidoptera; Gelechiidae). Environ.Entomol., 33:477486.

Srinivasa Rao, M., Manimanjari, D., Rama Rao, C.A., Swathi, P. and Maheswari, M. (2014). Effect of climate change on Spodoptera litura Fab. on peanut: a life table approach. Crop Protec., 66: 98-106.

Stinner, R.E., Gutierrez,A.P. and Butler, G.D. (1974).Analgorithm for temperature-dependent growth rate simulation. Canadian Entomol., 106: 519-524.

Tommaso, A., Sílvia, A. and Josep, J. (2007). Estimating the intrinsic rate of increase of Tetranychusurticae: which is the minimum number of immature individuals to consider? Exp. Appl. Acarol., 41: 55-59.

Tonnang, E.Z.H., Juarez, H., Carhuapoma, P., Gonzales, J.C., Mendoza, D., Sporleder, M., and Simon, R., Kroschel, J. (2013). ILCYM-Insect Life Cycle Modeling. Asoftware package for developing temperature-based insect phenologymodels with applications for local, regional and global analysis of insect population and mapping, International Potato Center, Lima, Peru. pp 175.
Tshiala, M.F., Botaim, J.O. and Olwoch, J.M. (2012). Leaf miner agromyzid pest distribution over Limpopo province under changing climate. Afr. J.Agric. Res., 7(48): 65156522 .

Tuan, S.J., Lee, C.C. and Chi, H. (2013). Population and damage projection of Spodoptera litura $(\mathrm{F})$ on peanuts (Arachishypogea L.) under different conditions using the age stage TWO-SEX life table. Pest Manag. Sci. http://dx.doi.org/10.1002/ PS.3618.

Vincent, P. J., Carrie, H.M.T. and Lois, C.C. (1997). Life tables for the Koa seed worm (Lepidoptera: Tortricidae) based on degree-day demography. Popul. Ecol. 26(6), 129298.

Wagner, T.L., Wu, H.I., Sharpe, P.J.H. and Coulson, R.N. (1984). Modeling distributions of insect development time: a literature review and application of the Weibull function. Ann. Entomol. Soc. Am., 77: 474-487.

Wang, R., Lan, Z. and Ding, Y.(1982). Studies on mathematical models of the relationship between insect development and temperature. Acta. Ecol. Sinica., 2: 47-57.

Xue, M., Pang, Y.H., Wang, H.T., Li, Q.L. and Liu, T.X. (2010). Effects of four host plants on biology and food utilization of the cutworm, Spodoptera litura.J. Insect Sci., 10: 22.

$\mathrm{Ya}^{\circ}$ ar, B. and Güngör, M.A. (2005). Determination of life table and biology of Colorado potato beetle, Leptinotarsadecemlineata Say (Coleoptera: Chrysomelidae), feeding on five different potato varieties in Turkey. Jap. Soc. App. Ent. Zool., 40: 589-596.

Zajac, M.A., Hall, F.R. and Wilson, M.C., (1989). Heat unit model for the development of meadow spittlebug (Homoptera: Cercopidae) on strawberry. Environ. Entomol., 18: 347-350.

Zamani, A.A., Talebi, A.A., Fathipour, Y. and Baniameri, V. (2006). Effect of temperature on biology and population growth parameters of Aphis gossypii Glover (Homopter: Aphididae) on greenhouse cucumber. J.Appl. Entomol., 130: 453-460. 